ÉTUDES

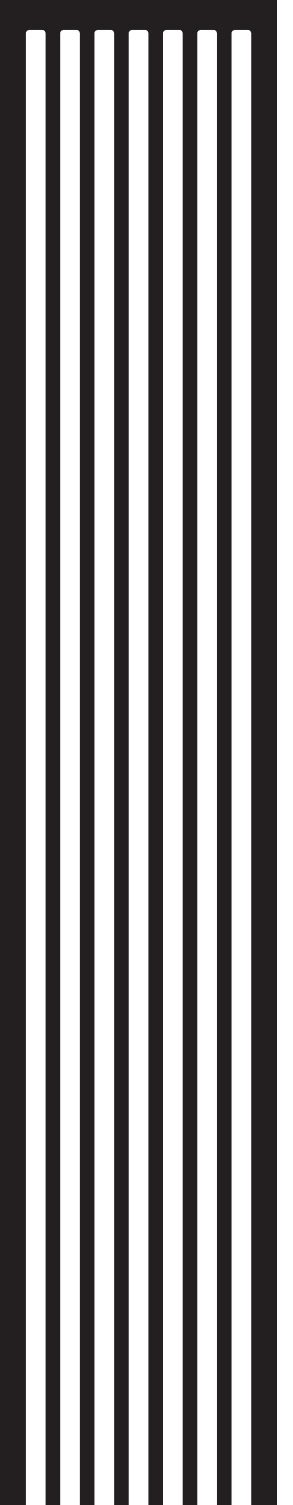





\title{
Ensayo y vida. El significado de Montaigne para Ezequiel Martínez Estrada
}

\author{
Essay and Life. The Meaning of Montaigne \\ for Ezequiel Martínez Estrada
}

Amán Rosales Rodríguez [arosales@amu.edu.pl]

Uniwersytet im. Adama Mickiewicza w Poznaniu, Uniwersytet Łódzki, Polonia

\section{RESUMEN}

En su extenso ensayo sobre la vida y obra de Miguel de Montaigne el ensayista argentino Ezequiel Martínez Estrada ofreció un estudio incisivo y bellamente escrito sobre el famoso escritor francés. El favorable retrato literario que Martínez Estrada traza del autor de Les Essais constituye no solo una especie de autorretrato intelectual del propio Martínez Estrada, sino también una reflexión profunda sobre la naturaleza del género ensayístico, del que el autor de Radiografía de la pampa fue un artista consumado. En este artículo se comentan ambos aspectos entrelazados: la identificación personal de Martínez Estrada con el individuo Montaigne y sus reflexiones sobre el ámbito y fines de la escritura ensayística. Martínez Estrada ligó la autenticidad del ensayo, y de la literatura en general, con su capacidad para reflejar del todo la riqueza de la vida, y, sobre todo, la vida del 'pueblo'.

\section{Palabras Clave}

Ezequiel Martínez Estrada; Miguel de Montaigne; literatura argentina; ensayo argentino

\begin{abstract}
In his book-length essay on the life and works of Michel of Montaigne, the notable Argentinean essayist Ezequiel Martínez Estrada offered an incisive and beautifully written study on the famous French writer. Martínez Estrada's sympathetic literary portrait of the author of the Essays constitutes no only a kind of intellectual self-portrait of Martínez Estrada himself but also a deep reflection on the nature of the genera of the essay, of which the famous author of X-Ray of The Pampa was an accomplished artist. In this article both intertwined aspects are commented: Martínez Estrada personal identification with the individual Montaigne and his reflections on the scope and aims of essay-writing. Martínez Estrada linked the authenticity of the essay-writing, but of literature in general with its capacity to fully reflect life's richness, and, above all, 'people's' life.
\end{abstract}

\section{KEYWORDS}

Ezequiel Martínez Estrada; Michel of Montaigne; Argentinean literature; Argentinean essay

RECIBIDO 2016-05-12; ACEPTADO 2016-10-10 


\section{Introducción}

El extenso capítulo que Ezequiel Martínez Estrada le dedicara a Miguel de Montaigne, "Montaigne, filósofo impremeditado y fortuito", en su obra Heraldos de la verdad (1957), bien podría haber constituido -como también los capítulos siguientes dedicados a Balzac y Nietzsche- un sólido libro independiente de interpretación sobre el escritor francés. La idea de incluirlo en un grueso volumen tripartito acaso delataría, pero en este caso multiplicada por tres, la conocida estrategia discursiva del ensayista argentino de exponer sus puntos de vista filosóficos, literarios, y político-sociales de la mano y con el apoyo de ciertas figuras intelectuales cuya autoridad moral están, para él, fuera de todo cuestionamiento: José Martí, Guillermo Enrique Hudson, Horacio Quiroga, José Hernández, son otras figuras, en este caso del ámbito hispanoparlante, que desempeñan una función similar en la escritura estradiana. El formidable triple soporte literario desde el que Martínez Estrada levanta su trama de comentarios (Montaigne, Balzac, Nietzsche) tendría que convencer a sus lectores, de una vez por todas, de la solidez de los argumentos. Ahora bien, ¿cuál es, en el caso específico de su trabajo sobre Montaigne, la idea o ideas centrales que Martínez Estrada, desea transmitir con su habitual vehemencia?, ¿en qué consiste el hondo significado que tiene para el argentino la obra ensayística de Montaigne?

Se trata de algunas convicciones fundamentales, de suyo estrechamente entrelazadas, que vale la pena intentar hacer explícitas desde un comienzo. En primer lugar, que la inmortalidad intelectual y literaria de Montaigne (como en forma idéntica, las de Balzac y Nietzsche) es consecuencia de que su escritura constituye una segregación pura de su vida y de la vida de su pueblo (o tierra, nación cultura) y no algo agregado o falso. Todo lo contrario, la ensayística de Montaigne constituye, para Ezequiel Martínez Estrada, un elemento orgánico integrado; o, mejor, una multiplicidad de elementos orgánicos esparcidos pero también integrados, de alguna manera, en una forma específicamente articulada: el tejido vital del hombre Montaigne. Este punto, por comentar con algo más de detalle en la tercera sección de este trabajo, tiene que ver con la defensa estradiana de la vinculación entre literatura y vida, a la que se refiere con insistencia en varios momentos de su carrera literaria.

En segundo lugar, en este trabajo se intenta mostrar que Martínez Estrada encontró en el género pleno y acabado del ensayo, modelado según su admirado Montaigne, el medio ideal de expresión -ameno e informativo a la vez- para trasmitir sus más íntimas convicciones con la más absoluta libertad. En el cuarto apartado se comentará con mayor detalle sobre el lugar del ensayo y sus características estructurales en la obra estradiana. Como su modelo Montaigne, Martínez Estrada halló en el ensayo -en forma similar a otros notables escritores argentinos del pasado y el presente- el vehículo idóneo para la expresión y defensa, a menudo cargadas de controversia y encendida polémica, de sus más hondas convicciones estéticas y políticas.

Existe, para Martínez Estrada, una convergencia esencial entre el ensayista Montaigne y el hombre Montaigne, una concordancia que es posible detectar como deseo en el propio ensayista argentino. El autor de Radiografía de la pampa modelará y moldeará desde una doble directriz, existencial y literaria, que puede estimarse derivada de la experiencia del autor de Les Essais y a partir de ese célebre trabajo ensayístico inaugural, su propia trayectoria intelectual y literaria posterior. Esta trayectoria descansa, fundamentalmente, en la creencia de que, con su palabras, el ensayo representa "la forma más holgada y libre de reglas para la expresión natural 
del pensamiento y la emoción" (Martínez Estrada 1957: 7). Y justo sobre el contenido de aquella obra inaugural de su labor ensayística escribiría Jorge Luis Borges unas líneas que se podrían aplicar a prácticamente todo el corpus estradiano posterior. Pues para Borges, las argumentaciones críticas estradianas, “a pura enumeración de hechos reales, sin ademanes descompuestos ni interjecciones, son de una eficacia mortal” (citado por Adam 1968: 220). Una apreciación general del ensayo estradiano se reservará para las reflexiones finales de este trabajo.

\section{El despertar de un compromiso social de la mano del ensayo}

La admiración estradiana hacia la obra de Montaigne no solo está justificada por las dotes literarias del autor de Les Essais, sino que hunde sus raíces en el más problemático terreno de la autobiografía del santafesino y en el dramático despertar de su vocación ensayística. Si bien la redacción de su trabajo sobre Montaigne comienza muchos años después de su decisión de consagrarse casi exclusivamente al género ensayístico, apenas cabe duda de que en la vida y obra de Montaigne, Martínez Estrada encuentra una justificación a posteriori de tal decisión. Es bien conocido que la tomó de manera consciente en el año 1930, en concreto el día 6 de septiembre de 1930, cuando un golpe militar consolida a las fuerzas autoritarias y derechistas en la Argentina de la mano del general José Félix Uriburu (véase Martínez Estrada 1969: 131-132).

Dicho evento marcó para Martínez Estrada un grado insólito de barbarie militar e incompetencia política, un grado para él solo superado por el arribo, años después, del fatídico movimiento peronista. A partir de entonces, la mirada inquisitiva de Martínez Estrada se posará con especial lucidez en los males del militarismo argentino y el populismo latinoamericano. Al respecto Christian Ferrer, biógrafo reciente de Ezequiel Martínez Estrada, escribe el siguiente comentario:

Con respecto a los militares, nunca les tuvo el menor aprecio. Consideraba que el ejército, que en su origen pudo haberse correspondido con los impulsos orgánicos del pueblo alzado y comandado por caudillos, luego respondió a la necesidad del latifundista de acabar con el indio, presa fácil, y a la del banquero que concedía empréstitos requiriendo a cambio una última ratio que garantizara su inversión. Distante de las idealizaciones de Jorge Luis Borges acerca de las proezas caballerescas de sus antepasados militares o del combatiente genérico de todas las épocas, Martínez Estrada percibía, en la exigua gloria militar de haber repelido tacuaras con cargas de fusilería o de haber arrollado huestes de muchachos paraguayos desarrapados con ayuda de otros dos ejércitos mejor provistos, el protagonismo que tarde o temprano asumirá el estamento militar sobre la política argentina, tras un supuesto acatamiento neutro a los civiles. (Ferrer 2014: 97)

La consolidación de las fuerzas autoritarias y militaristas en la Argentina hunde a Martínez Estrada en agrios sentimientos de desencanto y pesimismo que resultan, no obstante, sorprendentemente fértiles y prolíficos desde el punto de vista literario, pues a partir de aquel año comienza la parte más brillante de su carrera como despiadado ensayista crítico de la cultura y sociedad argentina, primero, de la latinoamericana y mundial también, más tarde. Recuérdese que dos años después de aquel golpe militar, en 1933, aparece la ya mencionada Radiografía de 
la pampa. Martínez Estada querrá trazar un cuarto de siglo después, durante la redacción de su libro Heraldos de la verdad y con base en la vida y obra de Montaigne, significativos paralelos con su propia existencia como ciudadano y escritor plantado tozuda y heroicamente ante el ascenso de la deshumanización política de su país.

La ensayística estradiana irrumpe, ya madura, en el momento en que se produce el levantamiento uriburista. Con corrección evalúa otro de sus biógrafos, Pedro Orgambide, el papel fundamental de acicate intelectual desempeñado por la revuelta militar contra Hipólito Yrigoyen: "El golpe militar oligárquico de 1930 [lleva a Martínez Estrada] a cuestionar la estructura misma del país, a tratar de ver más allá de las apariencias, a intentar un método, a ensayar un sistema de ideas que le permita observar profundamente no solo los hechos inmediatos sino aquellos otros que generan la historia" (Orgambide 1997: 80).

Durante los años treinta, Martínez Estrada extiende su desencantada mirada sobre un escenario apocalíptico, afín al contemplado algunos años después por otro ensayista-intérprete de Montaigne: Stefan Zweig. Este autor vienés, viviendo ya en la inmigración durante el apogeo europeo del nacionalsocialismo, escribe de una manera que hallaría concordancia plena con el Martínez Estrada defensor de la individualidad, en tanto que testigo doblemente traumatizado, primero por la revolución de Uriburu, por la de Perón años más tarde:

Sólo aquel que tiene que vivir en su alma estremecida una época que, con la guerra, la violencia y las ideologías tiránicas, amenaza la vida del individuo y, en esta vida, su más preciosa esencia, la libertad individual, sabe cuánto coraje, cuánta honradez y decisión se requiere para permanecer fiel a su yo más íntimo en estos tiempos de locura gregaria, y sabe que nada en el mundo es más difícil y problemático que conservar impoluta la independencia intelectual y moral en medio de una catástrofe de masas. (Zweig 2008: 11)

En otro lugar escribe Stefan Zweig acerca de la hermandad espiritual que siente hacia el ensayista francés. Sus palabras podría suscribirlas perfectamente el santafesino, pues para él también, la lectura de Montaigne confiere sólida justificación a su labor casi apostólica de denunciante de la corrupción social y el vicio político. Sobre todo con el arribo del peronismo y la posterior etapa de reacción militarista de los años cincuenta, Martínez Estrada ve desvanecerse, como Zweig, cualquier posibilidad de auténtico humanismo en una nación atrozmente desangrada y radicalmente desunida. Estas son las palabras de Zweig:

Es en esta hermandad de destino cuando Montaigne se convierte en mi hermano indispensable, en mi amigo, mi amparo y mi consuelo, pues ¡qué desesperadamente parecido es su destino al nuestro! Cuando Michel de Montaigne llega al mundo, una gran esperanza empieza a extinguirse, una esperanza igual a la que nosotros hemos vivido a principios de nuestro siglo, la esperanza de una humanización del mundo. (Zweig 2008: 14)

Dentro de este breve esbozo de paralelismo entre el escritor austriaco y el argentino, cabe aún destacar cómo ambos descubren también en el ensayo, tal y como ejemplarmente lo hallan en Montaigne, algo así como el bálsamo para el espíritu en tiempos de deshumanización. En el caso particular de Martínez Estrada, la opción por el ensayo, a partir de la década de los treinta, 
puede considerarse la respuesta anticipada a una de las preguntas más dramáticas formuladas por el texto de Zweig en los años cuarenta: "Cómo preservar mi alma propia e individual y su materia, que sólo a mí me pertenece, cómo sustraer mi cuerpo, mi salud, mis nervios, mis pensamientos, mis sentimientos, al peligro de caer víctima de una locura y de unos intereses ajenos? (Zweig 2008: 20)

El punto de vista que asumirá en adelante Martínez Estrada, es decir, con posterioridad al golpe uriburista, combinará elementos de lo elitista y lo popular; él mismo se autorretrata como un luchador del pueblo, aunque privilegiado por el arsenal retórico con el que dispone, en contra de la barbarie y la corrupción nacionales. Así escribirá algunos años después echando un ojeada retrospectiva a su quehacer literario: "Bien sé que la emancipación de los individuos y los pueblos se opera por otros medios, pero en el conjunto de los factores coadyuvantes a ese fin, la misión de la literatura es ésa, precisamente, de identificarse con el pueblo, de tener, aunque sublimadas, su alma, sus pasiones, sus ideas" (Martínez Estrada 1967b: 192-193).

Retornando al texto central objeto del presente trabajo, hay que indicar que, si se considera la época en que aparece, "Montaigne, filósofo impremeditado y fortuito", constituye un escrito sorprendentemente moderado y sereno. Considérese tan solo que el mismo año (1957) que Heraldos, Martínez Estrada publica Las 40, obra en la que el ensayista declara que su mensaje moral va dirigido más bien al futuro, puesto que en el presente sus exhortaciones morales resultan completamente inútiles. Asevera en dicha obra: "Hablo con los que aún no han nacido y que recogerán esta herencia de ignominia y de miseria que les legan los patricios y prohombres que viven y morirán satisfechos con la bendición papal.” (Martínez Estrada 2007: 20)

Tal es el tono que el Martínez Estrada ensayista hará completamente suyo a partir de los años treinta, cuando él mismo confiesa haberse alistado en el denostado bando de la barbarie nacional y en contra de la imperante civilización de la hipocresía: "Me recluté en las filas de los francotiradores anacrónicos de Sarmiento que de ese modo extraño vino a capitanearnos a los bárbaros" (Martínez Estrada 1967b: 165). Es notable la línea de coherencia que Martínez Estrada mantiene en su crítica de las instituciones sociales de su país, postura crítica que nace con su Radiografía y que no se debilita sino, antes bien, se fortalece en las décadas posteriores de su labor analítico-exploratoria de la "realidad profunda" argentina.

Las siguientes palabras que Martínez Estrada escribe sobre Montaigne, constituirían también una confesión sobre su situación personal durante los años de gestación de Radiografía de la pampa: "Para encontrarse a sí mismo le fue necesario encontrar antes al ensayo" (Martínez Estrada 1957: 9). Con otras palabras, en la medida en que Martínez Estrada encontró en el ensayo el medio idóneo tanto para el autoconocimiento personal como para el conocimiento de su entorno, es difícil determinar qué aspecto resulta más prioritario para él. Probablemente se trata de una falsa dualidad pues con esa obra él habría descubierto que su destino individual estaría en lo sucesivo ligado por completo al nacional. Prueba de ello sería su enfermedad de la piel de los años cincuenta que él atribuiría en su etiología al funesto ascenso del peronismo.

En todo caso, si, como bien ha escrito el especialista Pedro Aullón de Haro, el "ensayo propiamente dicho es el gran prototipo moderno, la gran creación literaria de la modernidad" y que en esa medida constituye "el modo más característico de la reflexión moderna" (Aullón de Haro 2006: 63), entonces hay que resaltar que Martínez Estrada asume del todo, mediante la 
práctica ensayística, su papel de intelectual moderno: en tanto que crítico mordaz de formas sociales anómalas y de las promesas incumplidas de la modernidad, pero también en tanto que firme defensor de algunos de sus ideales (democracia, justicia, solidaridad, etc.) más nobles. En la cuarta sección se volverá sobre el tema del ensayo como género y su elección como vehículo ideal de la comunicación interpersonal por parte del ensayista argentino.

\section{La escritura como segregación de la vida. El caso Montaigne}

Para Martínez Estrada la centralidad de Montaigne reside en que este autor logró fundir la vida, su vida, con la literatura, $y$, en concreto, con la forma más cercana al fluir vital de cada individuo: el ensayo: "Montaigne hace del oficio de escritor una necesidad orgánica y de su organismo entero un tema que se desarrolla como el argumento de un drama, viviendo. Todo cuanto le acontece en la vida social, física y mental, se refleja en sus escritos; éstos acaban por ser la imagen viva de su persona completa" (Martínez Estrada 1957: 20). Ante todo, Martínez Estrada manifiesta su admiración por el hecho de que Montaigne fue el primer autor que mediante su escritura no omitió decir nada de sí mismo. Escribe el autor de La cabeza de Goliat: "Porque no basta que alguien escriba sinceramente sobre sí mismo, que copie fielmente el texto de la vida en el texto literario. Ante todo es preciso que se opere ese curioso fenómeno de desdoblamiento y complemento de la personalidad, que consiste en vivir en función de lo que ha de escribirse y de escribir en función de lo que se ha vivido" (Martínez Estrada 1957: 20).

Martínez Estrada reitera en una misma página, con distintas imágenes, la idea de una íntima concordancia, casi de simbiosis orgánica, entre el escribir y el vivir: "La vida se convierte en un tema no propuesto artificialmente sino como el cuerpo del bailarín se convierte en danza [...] Así estos dos actos, vivir y escribir, entran en relación íntima e indestructible, como en los organismos distintos órganos de equilibrio y autorregulación. Después de trescientos cincuenta años no hay diferencia, efectivamente, entre lo que Montaigne pensó y vivió [...]" (Martínez Estrada 1957: 20).

Tal vez, no otra cosa habría deseado Martínez Estrada que se pensara de él y su trabajo como ensayista. Pues, al reiterar en varios lugares su formación autodidacta y los numerosos obstáculos y problemas, no solo económicos, que tuvo tenazmente que afrontar para dedicarse en forma del todo independiente, sin ataduras ni compromisos de ningún tipo, a su vocación literaria, el argentino refuerza la idea de una vida cuyo sentido final solo puede conferirlo la escritura, es decir, el tipo de escritura practicada por él.

La íntima relación entre ensayo y vida en la obra de Montaigne representa, para Martínez Estrada, un estado ideal que él mismo procuró alcanzar a lo largo de su carrera como observador crítico y cronista implacable de la descomposición social, pero también, como incomprendido (a su parecer) educador formal e informal de la juventud argentina. De Montaigne escribe, en relación con lo anterior: "El rasgo sobresaliente de su personalidad es la vocación de educador. Nada de pedagogía, ni de instrucción, sino de normas de conducta basadas en la experiencia, en el buen sentido común, encaminadas a la formación completa del individuo. Advierte: 'no es un alma, no es un cuerpo lo que se educa: es un hombre; es preciso no hacer de él dos"' (Martínez Estrada 1957: 32). 
La intención educadora reaparece constantemente en el ensayo estradiano y esto no debe sorprender pues, tal y como su autor lo concibe y se reitera en este trabajo, el ensayo es reflexión siempre dirigida al interior y al exterior, ensayar es un proceso que conlleva introversión y extroversión. El ensayo es vida en proceso de autorreflexión, y, a fortiori de proyección formadora, pues ni el ensayo ni la vida pueden quedarse enclaustrados en nichos de solipsismo. Por eso Martínez Estrada desea, como Montaigne, educar, aspira a encauzar la vida, pero no por la vía de la seca teoría, sino, como él lo ve también en Nietzsche, por la del ejemplo de una lozana "virtú" renacentista: "fortaleza, rectitud, inexpugnabilidad de principios y de conducta. Moral sin 'moralina”" (Martínez Estrada 1957: 37).

¿Pero cómo se consigue todo esto?, ¿dónde se localiza la fuente de una ensayística pedagógica nutrida de vida juvenil, vigorosa al máximo? Dicha fuente solo puede manar de las experiencias de la vida popular. Esto lo expresa claramente en su ensayo "El problema de los deberes sociales del escritor", a propósito de lo que Martínez Estrada califica de "genuina literatura”, es decir, literatura segregada por la vida y segregadora de vida. En dicho escrito se refiere, en efecto, a la obra de autores como "Aristófanes, Dante, Montaigne, Rabelais, Shakespeare, Cervantes, desde entonces, de lo más alto y fecundo de las letras hasta hoy. Todos ellos fueron 'pueblo' en las formas universales en que el pueblo piensa y siente, como creador de nuevas formas de vida" (Martínez Estrada 1967a: 169).

La escritura conectada orgánicamente con la vida del pueblo, tal y como la practicaron, entre otros, los autores citados en el párrafo anterior, la denomina también Martínez Estrada una "literatura de progreso" que educa precisamente mediante el ejemplo. Ambiciosamente, se trata de una literatura que entiende al ser humano y en particular al artista y escritor, como explorador, pionero de nuevos territorios - de ahí la consabida admiración de Martínez Estrada por los "viajeros ingleses" en la Argentina del siglo antepasado-, pero además como eliminador de creencias e ideas perniciosas. El ensayista, en particular, imbuido de las energías vitales de renovación, "debe inventar, crear, agitar, ensayar y remover en el área de sus actividades, que es prácticamente toda la que abarca la sociedad civilizada” (Martínez Estrada 1967a: 171).

Estas ideas las esboza igualmente Martínez Estrada, con profusión, en su ensayo tardío "Prolegómenos a una revaluación de las letras argentinas", publicado en Cuba en 1960. En este trabajo, el argentino desarrolla, naturalmente bajo el fresco impacto de la Revolución castrista, sus ideas en torno a una literatura 'comprometida' con la vida y las raíces populares. No se trata, claro está, de reflexiones de nuevo cuño en su obra, pero sí rejuvenecidas por su reciente experiencia cubana. Para Martínez Estrada, el grueso de la literatura argentina constituye un torso deforme, artificial y torpemente erigido, pues carece de alma popular en tanto que impulso formativo de sus contenidos. Aquellos escritores que a lo largo de la historia del país se han atrevido a proclamar, produciendo "documentos vivos de la realidad cotidiana", la verdad sobre el país y sus instituciones, habrían sido marginados de las celebraciones nacionales. La lista incluye algunos de los héroes favoritos de Martínez Estrada, quien se permite incluirse en la lista de los marginados intelectuales de su país:

Quien revela la verdad, muere. Es el 'destierro’ de Moreno, Rivadavia, San Martín, Echeverría, Sarmiento, Alberdi. Agustín Álvarez, Lisandro de la Torre, Juan Álvarez, Ingenieros, Groussac y algunos de nosotros.” (Martínez Estrada 1967b: 19) Agrega aún el autor: “En términos categóricos, 
nuestra gran literatura, que es la realista, verista, honrada, humilde, extraña al jingoísmo de la buena sociedad letrada y, por añadidura, la bien escrita (desde El Matadero hasta Don Segundo Sombra), o es prácticamente desconocida por el gran público, o utilizada por la intelligentsia como dechado de argentinidad." (Martínez Estrada 1967b: 20)

El volumen que incluye el ensayo anterior también contiene otros textos significativos acerca de lo que Martínez Estrada estima como una relación auténtica y sana entre la vida social concreta y la labor literaria. Aunque por supuesto el acento se coloca en la vida social y no en la individual que Martínez Estrada subordina por los años sesenta a los imperativos de la Revolución (cubana), sus reflexiones apuntan a lo que se ha venido recalcando en este trabajo respecto de la lectura estradiana de Montaigne: la expresión del mundo subjetivo del escritor alcanza su máxima cualidad cuando dicho mundo nace y se alimenta de un terreno de conexiones sociales comunes que el artista sensible siempre logrará recrear, sea que se trate de una exposición autobiográfica, ensayística o ficcional. Considérese algunos ejemplos más de cómo Martínez Estrada concibe una fusión genuina de lo individual con lo social y cómo también llama la atención, agria y severamente, de su ausencia en gran parte de la creación literaria de su país.

Así, en el texto "Literatura propia y apropiada" el juicio estradiano es, como de costumbre, severísimo: "En general nuestra producción es falsa -copia intencionada de otras-o de baja calidad" (Martínez Estrada 1967b: 197). Puesto que "el verdadero sentido de una literatura es responder a una realidad concreta", la argentina carece de verdadero sentido, por eso continúa: "Ante este pavoroso problema estamos: ante una cultura sin raíces en la vida real y de una vida informe que por debajo de ella, sin haber podido ser sofocada, pugna por proyectar a través de sus resquicios tallos silvestres desde sus raíces sombrías." (Martínez Estrada 1967b: 199) Y en el propio inicio de otro texto del mismo volumen, "En busca de bueyes perdidos", declara: "Antes de acudir a un historiador de nuestras letras, suponiendo que ya hubiera alguno, necesitaríamos el auxilio de un agrimensor. No sabemos en qué país vivimos, qué forma tiene, ni qué fronteras, ni qué relieve” (Martínez Estrada 1967b: 201). De una de sus obras predilectas, Martín Fierro, asevera que contiene, pese a sus defectos, "virtudes exquisitas", como "la sencillez sin afectación, la ausencia de todo pintoresquismo efectista y la honradez con que se acepta la realidad, en lo bueno y en lo malo, si puede decirse así” (Martínez Estrada 1967b: 201).

Poco antes de la publicación de Heraldos de la verdad, Ezequiel Martínez Estrada pronuncia un significativo discurso ("Literatura y vida", 1956) que se concentra en la no siempre obvia conexión, para él, de la actividad intelectual y literaria con un determinado entorno culturalnacional. La conclusión del texto publicado, no exenta ni de pasión ni de patetismo, reza así: "La literatura debe ser no sólo reflejo de la vida de un pueblo sino el órgano de penetración en las entrañas de la tierra y del habitante, el vínculo de solidaridad y simpatía, la argamasa de la solidaridad humana que empieza por la solidaridad familiar" (Martínez Estrada 1967b: 158). Por el contrario, en la Argentina no ha existido, hasta ahora, de nuevo según él, esa necesaria argamasa que sirva para integrar los elementos heterogéneos de una nación en pugna permanente consigo mismo.

Hay, desde luego, matices de la posición anterior que son reminiscentes de un dudoso telurismo cultural que Martínez Estrada o no advierte o simplemente asume sin mayores problemas. La proclividad hacia el telurismo ocasiona que el autor de la monumental Muerte y 
transfiguración de Martín Fierro asocie la quebrada relación argentina de lo literario con lo popular (manifestación privilegiada de las fuerzas vitales), con la ausencia de auténticas y profundas raíces indígenas -violentamente cortadas en el pasado de la nación. Así lo expresa en un texto de Cuadrante del pampero, en donde asevera de las clases sociales de su país lo siguiente:

A la alta y a la baja plebe, como a la media si es que existe, le ha faltado el elemento indígena (la cepa para el injerto de la culturación europea), y esto ha dificultado el sentido mítico de la tierra, de las cosas, de los seres que con nosotros forman la gran familia y el hogar nacionales. Porque nos falta este eslabón que une la cadena de la naturaleza a la cadena de la sociedad civilizada, flotamos sin raíces, como el irupé, a la deriva. (Martínez Estrada 1956: 116)

El especialista argentino Eduardo Grüner escribió las siguientes palabras sobre la naturaleza del gesto ensayístico: "Ensayista es quien puede decir, como Kafka: 'no escribimos según lo que somos: somos según aquello que escribimos.' Lo importante aquí es el uso del plural: ensayista es el que sabe que nunca escribe solo (y su soledad consiste en saber eso) porque su escritura es la que permite también que se escriba -que se inscriba- el autor con el cual 'ensaya"' (Grüner 2013: 29). Estas palabras se pueden relacionar con el caso de Martínez Estrada, para quien resulta fundamental acentuar que la ensayística de Montaigne exuda absolutamente vida pues se trata de una obra en la que resuena, al unísono, la mismidad y la otredad. Montaigne vive su vida conforme escribe y su escritura es efecto de su vivir. no escribe sobre su vida, la escribe. Según el argentino, la existencia humana no es concebible al margen de dicho juego entre lo objetivo y lo subjetivo:

"Montaigne procede como los poetas, revelando en sí pensamientos y sentimientos impersonales e intemporales: cuanto más subjetivo es, mayor cantidad de otros representa. En sus ensayos Montaigne se exhibe tal y como es [...] y lo que vemos en su retrato es un inquietante parecido con nosotros. Su rostro de sinceridad se parece mucho al rostro que nos vemos en el espejo, frente a frente" (Martínez Estrada 1957: 42). Esta es una de las claves de la escritura estradiana tal y como se revela directamente a través de su lectura de Montaigne: el autorretrato que Montaigne traza de sí mismo no es un ejercicio solipsista, sino que cuanto más dice o sugiere de si mismo, más también otorga a sus lectores en cuanto a un conocimiento general de la condición humana.

En su lectura de la figura del ensayista Montaigne, el santafesino efectúa una sui generis maniobra interpretativa. Parte de lo que él considera un compromiso primordial de Montaigne con la expresión de su mundo subjetivo (configurado a partir de experiencias personales y de lecturas de los clásicos) para pasar -de forma casi imperceptible- a vincular el ámbito de subjetividad con el de la esfera cultural y social específica del autor. Es más, Martínez Estrada parece considerar que aquel primer mundo de subjetividad del erudito y gentilhombre Montaigne es auténtico justo porque es un reflejo fiel y honesto del segundo, el del simple 'pueblo' y sus tradiciones.

Es cierto que este último giro interpretativo del argentino aparecerá plenamente desarrollado, aunque no explicitado, solo algunos años después, en sus trabajos más tardíos, cuando su desencantada mirada retrospectiva sobre lo que ha significado el peronismo en su país se combine y atempere con el talante optimista de su compromiso cubano. Desde esa posición tardía 
en su vida y obra, Martínez Estrada ya podrá relacionar la buena fe y sinceridad intelectual de Montaigne con su propia actitud de intelectual comprometido con lo popular.

En resumen, de la posición estradiana más tardía puede derivarse, en forma tentativa, la siguiente constatación: aunque las apariencias parezcan desmentirlo, la calidad moral del ensayista Montaigne está firmemente apoyada, de modo semejante a otros grandes artistas y escritores, en el más genuino espíritu popular. Aún se volverá sobre esta temática en el apartado siguiente, pero relacionándola de modo más directo con la elección estradiana del ensayo como medio predilecto para la diseminación y defensa de sus ideas.

\section{La centralidad de la vía ensayística}

La estrategia lectora estradiana respecto de Montaigne, pero también su concepción general de la labor ensayística, podría explicitarse aún más desde las palabras de otro estudioso del ensayo argentino, A. Giordano, que buscan desarrollar una idea del ensayo (literario) a partir de lo que su autor entiende como una forma privilegiada de dialogar 'desde' dentro con la literatura. De acuerdo con la propuesta de Giordano, la escritura ensayística participa del juego literario duplicándolo de un modo revelador en sus reglas y resultados - por el contrario, el ensayo o tratado académico-científico miraría el juego desde fuera. Con palabras de dicho autor:

El ensayo [...] como diálogo con la literatura. 'Diálogo’ debe tomarse aquí en un sentido próximo al de la 'conversación' heideggeriana [...] es decir, al de una interpelación que se realiza no desde fuera, al amparo de un exterior en el que encuentra reposo quien interpela [...] sino en el interior del campo interpelado, comportándose 'según su modo'. La búsqueda del ensayo, en la que el diálogo se instituye, 'acompaña' al movimiento de la literatura, lo duplica, y encuentra en esa estrategia mimética la ocasión de dar testimonio de lo que está en juego [...] por el hecho de que una palabra como la literaria se enuncie. (Giordano 2005: 223-224)

La apelación al ensayo como forma estratégica del diálogo intelectual -en concreto, de esa duplicación mimética del trabajo literario, según la concepción de A. Giordano- es una constante en la creación literaria de la Argentina. Así, por ejemplo, la especialista T. Alfieri, escribe acertadamente sobre este punto: "El género [del ensayo], cuya amenidad es un requisito de su prosa, promete ideas nuevas, formas originales y representa tanto en calidad como en cantidad una especialización notable de la literatura argentina" (Alfieri 2007: 289). Todavía indagando en las influencias textuales centrales que nutrieron la producción estradiana en ese campo, esa misma autora constata que

si Montaigne y Bacon fueron los padres del ensayo occidental moderno, [Mariano] Moreno y [Bernardo de] Monteagudo fueron los padres del ensayo argentino, porque el ensayo argentino nace como ensayo de interpretación nacional y va a vehiculizar desde los primeros tiempos las preocupaciones de los argentinos respecto de su nación, será un instrumento de lucha, pero también un espacio literario, un lugar desde donde se hará la patria tan fuertemente como en una mismísima batalla. (Alfieri 2007: 292) 
Si la escritura o literatura auténtica es, para Martínez Estrada, una segregación de la existencia, entonces el ensayo aparece en él, en tanto que discípulo de autores tan diversos como Bacon, Montaigne, Moreno, Monteagudo, y, desde luego, Sarmiento, como el recurso ideal para encauzar y fijar de algún modo las energías vitales e inquietudes sociales de un periodo histórico-social y político determinado. La relación entre ensayo (o literatura en general) y vida, tal y como la entiende Martínez Estrada tiene que ver con la idea de que todo arte, toda literatura, concebidos y ejecutados al margen de experiencias vitales muy concretas (angustiosas, apremiantes, dolorosas, etc.) solo pueden arrojar resultados no solamente artificiales sino artificiosos.

Puesto que la vida contiene mucho más que lo que conceptos y teorías pretenden aprehender intelectualmente, el artista está convocado, con $s u$ vida, en primer lugar, a dar expresión plena a esa riqueza inagotable del ser. El ensayista deber ser ejemplo vivo de su compromiso con la escritura y la vida. De ahí que el ensayo en general (y no solamente el más puntualmente autobiográfico o confesional) represente el medio idóneo -y Montaigne su máximo practicantepara expresar ese doble movimiento hacia adentro y hacia afuera de la sensibilidad artística en búsqueda de sí misma y de su manera de conectarse con el mundo. El ensayo parte de un deseo de autoconocimiento que no puede prescindir de la proyección al mundo de la vida social. De forma muy pertinente describe el filósofo francés M. Merleau-Ponty el inicio de este proceso en el hombre Montaigne y su obra:

El conocimiento de sí mismo en Montaigne es diálogo consigo mismo, es una interrogación dirigida a este ser opaco que es él y del que espera respuesta, es como un 'ensayo' o una 'experiencia’ de sí mismo. Se propone una investigación sin la cual la pureza de la razón sería ilusoria y además impura. Nos asombramos de que nos haya querido contar incluso los detalles de su humor y de su temperamento. Y es que para él toda doctrina, separada de lo que hacemos, corre el peligro de ser falaz, e imaginó un libro en el que por una vez se encontrarán expresadas no solamente ideas, sino también la vida misma en la que ellas aparecen y que modifica su pensamiento. (Merleau-Ponty 1964: 248-249)

La centralidad del ensayo en la escritura estradiana se explica, en parte, en virtud de la relación entre autoridad y libertad que articula el desarrollo de cualquier tema y determina las posibilidades creativas de cualquier autor. No obstante, en el caso del argentino dicha relación adquiere un tono especial en razón de la peculiar personalidad del escritor. La libertad máxima se la otorga a su literatura un indignado ciudadano, Ezequiel Martínez Estrada, quien no concibe la actividad literaria desvinculada de un alto sentido de responsabilidad cívica y social. La autoridad de su palabra mana también de su autodesignada posición de acusador y enjuiciador de su país; se trata de una posición incuestionable de soberanía moral que le permite ubicarse por todo lo alto como observador privilegiado, por incorruptible, de la triste realidad política de su país.

Afortunadamente, gracias a su dominio de los medios expresivos de la prosa de ideas, Martínez Estrada consigue impregnar de belleza inusual mensajes de indignación y protesta que de otro modo, en autores menores, no causarían mayor impacto emotivo o intelectual y no alcanzarían sino un modesto nivel de estridencia panfletaria. A este respecto merece una mención 
especial otro aporte sobre la naturaleza del ensayo, se trata de un pasaje de J. Starobinski: "el ensayo debe siempre estar atento a la respuesta precisa que las obras o los hecho interrogados devuelven a sus preguntas. No debe romper nunca su servidumbre a la claridad y belleza del lenguaje. Por fin, cuando llegue el momento, el ensayo soltará amarras e intentará a su vez ser él mismo una obra, con su propia y temblorosa autoridad" (Starobinski 1983: 40). Constituye un mérito encomiable que la prosa ensayística de Martínez Estrada alcance al final, sin haber comprometido nunca su pacto con "la claridad y belleza del lenguaje" esa forma de "temblorosa autoridad” que es la única, a fin de cuentas, que cabe esperar de un género constituido desde la provisionalidad y lo tentativo.

La fidelidad del ensayista o literato con la vida común representa también de suyo un compromiso con los demás, especialmente con los más desfavorecidos socialmente. Se trata, como ya se vio con mayor detalle en la sección anterior, de una convicción 'populista' que aparece temprano en la ensayística del argentino, y que irá adquiriendo una importancia cada vez más grande con el correr de los años hasta culminar, en los últimos años de vida de Martínez Estrada -coincidentes con su compromiso total con la Revolución cubana-, en una posición de radical activismo social con tintes dogmáticos. En ese momento converge en el argentino la actividad ensayística con la revolucionaria, el ensayo literario es reflejo íntegro, en la práctica, de ensayo revolucionario.

Para concluir esta sección, una interesante concordancia con el pensamiento estradiano de esos últimos años cincuenta y comienzos de los sesenta puede establecerse aquí, de forma clara y directa, con el siguiente fragmento de un discurso (original de 1969) de Elias Canetti: "La verdadera profesión de escritor consistiría, para mí, en una experiencia forzosa con todo tipo de seres humanos, con todos, pero en particular con los que menos atención reciben, y en la continua inquietud con que se lleva a cabo esta práctica, no mermada ni paralizada por ningún sistema" (Canetti 2013: 580).

\section{Algunas reflexiones finales}

Es difícil encontrar otro fragmento de "Montaigne, filósofo impremeditado y fortuito" como el que se reproduce a continuación, que condense en forma tan exacta y elocuente los dos elementos centrales objeto del presente: a) la concepción estradiana de la creación ensayística, y b) su aprecio, asumido como guía personal, por la fundamental equivalencia ensayo-vida en la personalidad de Montaigne, pues este autor, afirma el argentino en dicho fragmento, "hizo del ensayo su imagen literaria fiel; no con su fisonomía y estatura verdaderas, sino con su personalidad. Como él, es un ser proteico, amorfo, susceptible de transformarse hasta adquirir un cuerpo vivo, una cara, una voz. Su estilo es igual a su pensamiento y nos parece imposible que hubiera podido expresarse en ninguna de las formas tradicionales para la prosa y el verso, que imponían pautas y leyes de juego previas” (Martínez Estrada 1957: 9).

Este texto tan sugerente puede leerse a partir de sus resonancias autobiográficas, pues, como Montaigne, el santafesino aspira a que su escritura sea, como ya se destacó en la segunda sección del presente trabajo, un reflejo fiel e integral de su personalidad; es decir, que el texto ensayístico sea una segregación de su vida y su vida una forma modelada por el discurrir libre del 
ensayo. El texto expresa el deseo -ingénito al discurso ensayístico, fortalecido con el ejemplo de su modelo literario francés- de volver equivalentes el estilo y el pensamiento.

Por otro lado, si la escritura ensayística es un género marcado por la provisionalidad y el tanteo, por su carácter inconcluso y por preferir la incierta marcha en el camino antes que la llegada triunfal a un destino, ¿cómo compaginar todo esto en un ensayista como Martínez Estrada? Cuando el argentino escribe en su texto sobre Montaigne que lo "común es que el ensayo se desarrolle desarrollándose, viviendo", y que, por lo tanto, al ensayo "le está permitido serlo todo" (Martínez Estrada 1957: 8), está ofreciendo una suerte de contestación a dicha interrogante. Pero esta especie de respuesta es desde luego muy problemática, pues con ella se está sugiriendo, nada menos, que la libertad expresiva del ensayo está determinada por su fidelidad absoluta a un punto de vista personal: la libertad del ensayo solo puede residir en que en él se refleja auténticamente la vida, es decir, $m i$ vida.

Pero entonces, ¿en qué se diferencia todo lo anterior de la adopción de una postura dogmática? En vano hay que esperar un tratamiento satisfactorio en Martínez Estrada de esta cuestión. Para él, la escritura ensayística tiene valor en cuanto corresponda a una profunda convicción interna que no puede calificarse de dogmática, al menos él rechazaría de plano que tal fuera su caso. Quizá lo más que podría aventurarse respecto del punto anterior es que Martínez Estrada opera con una idea del ser humano que toma muy en cuenta, como lo recuerda Erich Auerbach escribiendo, en su obra fundamental, Mimesis, sobre la "idea de hombre muy realista" que tiene Montaigne, "que él es un ser oscilante, sujeto a las variaciones del ambiente, del destino y de sus propios movimientos interiores” (Auerbach 1950: 270).

Es decir, para el argentino, el peligro del dogmatismo se aminora dentro del espíritu ensayístico en la medida en que este nunca reposa satisfecho sobre ninguna postura o punto de vista, por muy confiables o seguros que puedan parecer sus fundamentos teóricos en determinado momento. La vida ( $m i$ vida) es movimiento, es cambio y modificación constantes; el gesto ensayístico, animado por un incesante flujo creativo y crítico, aspira a emular dicho movimiento que no concluye sino con el cese mismo de la vida.

\section{Referencias bibliográficas}

Adam, C. (1968). Bibliografía y documentos de Ezequiel Martínez Estrada. La Plata: Universidad Nacional de la Plata.

Alfieri, T. (2004). La Argentina de Ezequiel Martínez Estrada. Buenos Aires: Leviatán.

Auerbach, E. (1950). L’humaine condition. In Mimesis. La representación de la realidad en la literatura occidental, trad. J. Villanueva y E. Ímaz. (pp. 265-291). México: FCE.

Aullón de Haro, P. (2006). El problema de la teoría del ensayo y el problema del ensayo como forma según Theodor W. Adorno. Revista Educación Estética, 2, 55-76.

Canetti, E. (2013). Arrebatos verbales. Obra completa IX, trad. J. J. del Solar. Barcelona: Debolsillo.

Ferrer, C. (2014). La amargura metódica. Ezequiel Martínez Estrada. Buenos Aires: Sudamericana.

Giordano, A. (2005). Modos del ensayo. De Borges a Piglia. Buenos Aires: Beatriz Viterbo.

Grüner, E. (2013). Un género culpable. Buenos Aires: Ediciones Godot. 
Martínez Estrada, E. (2007). Las 40 / Exhortaciones. Buenos Aires: Las Cuarenta.

- (1969). Leer y escribir. México: Joaquín Mortiz.

- (1967a). En torno a Kafka y otros ensayos. Barcelona: Seix Barral.

- (1967b). Para una revisión de las letras argentinas. (Prolegómenos). comp. E. Espinoza. Buenos Aires: Losada.

. (1957). Montaigne, filósofo impremeditado y fortuito. In Heraldos de la verdad (pp. 5-96). Buenos Aires: Nova.

. (1956). Cuadrante del pampero. Buenos Aires: Deucalión.

Merleau-Ponty, M. (1964). Lectura de Montaigne. In Signos (pp. 244-261). Barcelona: Seix Barral.

Orgambide, P. (1997). Un puritano en el burdel. Rosario: Ameghino.

Starobinski, J. (1983). ¿Es posible definir el ensayo? Cuadernos Hispanoamericanos, 575, 31-40.

Zweig, S. (2008). Montaigne. Trad. J. Fontcuberta. Barcelona: Acantilado. 